\title{
Study of the effectiveness of the third generation polyamide- amine and polypropylene imine dendrimers in removal of reactive blue 19 dye from aqueous solutions
}

\author{
Sepideh Sadeghi ${ }^{1,2}{ }^{\mathbb{D}}$, Ghazal Raki ${ }^{1,2}$, Asrin Amini ${ }^{1,2}$, Nezamaddin Mengelizadeh ${ }^{1,2}$, Mohammad Mehdi Amin ${ }^{1}$, \\ Majid Hashemi ${ }^{1,2,3 * \mathbb{D}}$ \\ ${ }^{1}$ Department of Environmental Health Engineering, School of Health, Isfahan University of Medical Sciences, Isfahan, Iran \\ ${ }^{2}$ Student Research Committee, Isfahan University of Medical Sciences, Isfahan, Iran \\ ${ }^{3}$ Environmental Health Engineering Research Center, School of Health, Kerman University of Medical Sciences, Kerman, Iran
}

\begin{abstract}
Background: Dye and colored materials cause health risks in water and therefore, must be removed from water supplies and wastewater. The aim of this study was to evaluate the effectiveness of the third generation poly(amidoamine) (PAMAM) and poly (propylene imine) dendrimers (PPI-G3) in the removal of reactive blue 19 (RB19) dye from aqueous solutions and determine the optimum conditions for the removal.

Methods: This study was performed in a laboratory and batch scale. In this study, synthetic wastewater was examined with three different concentrations of RB19 $(25,50$, and $100 \mathrm{mg} / \mathrm{L})$, different $\mathrm{pHs}$ $(3,7$, and 10$)$, various amounts of dendrimer $(0.4,0.8,1.2$, and $1.6 \mathrm{~g} / \mathrm{L})$, and at different times $(15$, 30 , and 60 minutes) during the adsorption process. The remaining amount of dye was measured by spectrophotometer at $592 \mathrm{~nm}$ wavelength. Langmuir and Freundlich isotherms were also tested. Results: The results showed that by increasing the reaction time and adsorbent dosage, the rate of dye removal increased while by increasing the initial dye concentration and $\mathrm{pH}$, the dye removal efficiency was significantly decreased. In this study, with increase of $\mathrm{pH}$ from 3 to 10 , dye removal efficiency at a concentration of $25 \mathrm{mg} / \mathrm{L}$, decreased from $72 \%$ to $20 \%$ and $88 \%$ to $17 \%$ by PAMAM and PPI dendrimers, respectively. Excel software was used for data analysis.

Conclusion: Both adsorbents had a good dye removal efficiency, but PPI dendrimer was more effective in removing RB19. Adsorption data followed the Langmuir isotherm.

Keywords: Adsorption, Wastewater, Dendrimer, Polyamide amine, Polypropylene imine

Citation: Sadeghi S, Raki G, Amini A, Mengelizadeh N, Amin MM, Hashemi M. Study of the effectiveness of the third generation polyamide-amine and polypropylene imine dendrimers in removal of reactive blue 19 dye from aqueous solutions. Environmental Health Engineering and Management Journal 2018; 5(4): 197-203. doi: 10.15171/EHEM.2018.27.
\end{abstract}

Article History:

Received: 6 July 2018

Accepted: 5 September 2018

ePublished: 6 October 2018

\section{Introduction}

The dye is one of the most important pollutants in industrial wastewater that is widely used in industrial sectors such as textile, leather, cosmetics, paper making, food processing and pharmaceutical industries $(1,2)$. Reactive dyes are water-soluble and anionic that are largely used in the textile industry. Reactive blue 19 (RB19) with its special chemical structure is one of the anthraquinone dyes which are the most widely used in textile, after azo dyes. This dye has relatively low fixation efficiency on the fiber and thus, considerable amounts of waste can be imported to wastewater. Since this dye is stable in natural environments and highly resistant to light, chemical agents and biological degradation, discharging wastewater containing dye into the environment will cause irreversible and serious problems $(3,4)$. Due to the low bio-decomposition of dyes, the conventional biological wastewater treatment processes are not effective in dye wastewater treatment. The colored wastewater is usually treated by physical or chemical methods such as coagulation and flocculation, precipitation, adsorption, membrane filtration, electrochemical techniques, ozonation and etc. The adsorption process is one of the physicochemical processes developed due to the low cost, ease of operation, flexibility, and simplicity for treatment of wastewater containing dye, organic materials and metals $(5,6)$. One of the newest adsorbents is dendrimer. Dendrimer is a Greek term composed of two parts: "dendron" meaning 
"tree" and "meros" meaning "part" and implies the treelike branched structure of this group of compounds (7). The structure of dendrimers is composed of 3 parts: An inner core, shell (generation) comprising repeating units, and terminal functional groups $(8,9)$. Depending on the number of generations, dendrimers include a wide range of dimensions often in the nanometer range so that in the third generation (G3), their dimension is equal to insulin hormone (5). Dendrimer as a nanomaterial (7) and due to its large surface, has high and effective capability to remove the contaminants (10). The main features of dendrimers are having many active endgroups as well as the blank spaces between the branches of the internal connector that have the ability to attract and imprison foreign molecules such as water, dye and other materials by chemical bonding and encapsulation (9).

These polymers are of great importance in various fields such as medical and industrial applications and pharmaceuticals as a material to eliminate germs and in the field of water and wastewater treatment, to remove pollutants $(11,12)$. Table 1 shows different types of dendrimers including polyamide amine-organosilicon (PAMAMOS), poly(amidoamine) (PAMAM), polypropylene imine (PPI), chiral, liquid crystal, Tecto, hybrid, multilingual and Micellar (9). Many studies have been done on the use of dendrimers to remove pollutants from the environment. Patel et al in a study examined the removal of metal ions $\mathrm{Cu}^{2+}, \mathrm{Ni}^{2+}$ and $\mathrm{Zn}^{2+}$ of water using G1, G2, and G3 dendrimers with the number of hydroxyl groups 8, 32 and 128 as adsorbents (13). In another study, PPI and chitosan were evaluated as a biopolymer to remove reactive black 5 and reactive red 198 (5). The microparticles of polyamide imine-chitosan have been used as an adsorbent for the removal of reactive blue 21 (14). In this study, the G3 (PAMAM and PPI) dendrimers were used as the adsorbents for the removal of RB19 dye from wastewater.

\section{Material and Methods}

This study was conducted discontinuously (batch) on a laboratory scale. In this study, the third generation PAMAM and PPI dendrimers were purchased from the Institute of Tehran Paint, and their structural form is provided in Figure 1 (15). The dye used in this study, was purchased from Sigma-Aldrich and other chemicals used

Table 1. Characteristics of reactive blue 19 dye

\begin{tabular}{ll}
\hline Chemical Formula & $\mathrm{C}_{22} \mathrm{H}_{16} \mathrm{~N}_{2} \mathrm{Na}_{2} \mathrm{O}_{11} \mathrm{~S}_{3}$ \\
\hline Molecular Weight & $626.5 \mathrm{~g}$ \\
Trade Name & Remazol Brilliant Blue $\mathrm{R}$ \\
Chemical Structure
\end{tabular}

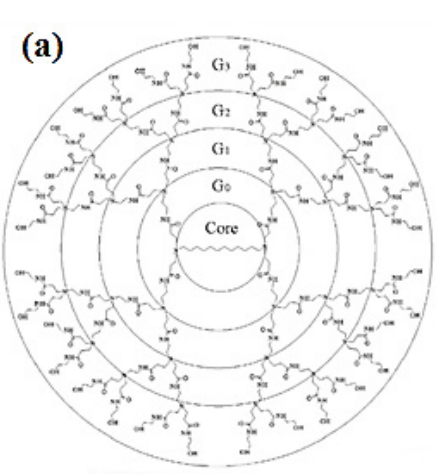

(b)

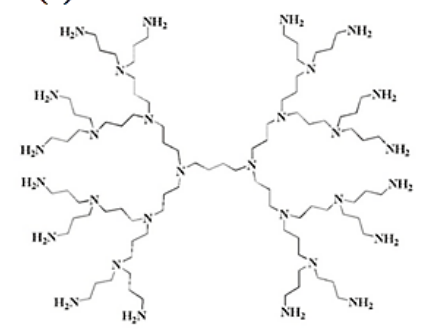

Figure 1. PAMAM (a) and PPI (b) dendrimers.

in the experiments, were obtained from Merck (Germany). Characteristics of RB19 dye are provided in Table 1 (16). In order to prepare the wastewater, the dye stock solution was created by solving the appropriate amount of RB19 powder in distilled water and then, different concentrations $(25,50$, and $100 \mathrm{mg} / \mathrm{L})$ were examined. In the present study, the influence of different adsorbent dosage $(0.4,0.8,1.2$, and $1.6 \mathrm{mg} / \mathrm{L}), \mathrm{pH}(3,7$, and 10$)$, initial dye concentration $(25,50$, and $100 \mathrm{mg} / \mathrm{L})$ and reaction time $(15,30$, and $60 \mathrm{~min})$ on dye removal was investigated. In order to mix and make a proper contact between the adsorbent and dye, a mechanical shaker at $250 \mathrm{rpm}$ was used. The adsorbent was separated from the wastewater using membrane filter ( 0.45 micron in diameter). Sulfuric acid and sodium hydroxide $1 \mathrm{~N}$ were used to adjust the $\mathrm{pH}$. The remaining dye concentration was measured using a UV/Vis spectrophotometer (Optima SP-3000 Plus model, Japan) at $592 \mathrm{~nm}$. The amount of dye adsorbed at equilibrium time $\left(\mathrm{q}_{\mathrm{e}}\right)$ and dye removal efficiency (E) were respectively calculated using equations (1) and (2) (16).

$$
\begin{aligned}
& q_{e}=\frac{V}{M} \times\left(C_{0}-C_{e}\right) \\
& E=\frac{C_{0}-C}{C_{0}} \times 100
\end{aligned}
$$

In these equations, $C_{0}$ and $C e$ respectively show the initial and final concentration of the dye $(\mathrm{mg} / \mathrm{L}), V$, volume of the solution (L), $M$, adsorbent mass $(\mathrm{g}), q_{e}$, adsorption capacity at equilibrium time $(\mathrm{mg} / \mathrm{g})$, and $E$, dye removal efficiency (\%) (17). Langmuir and Freundlich adsorption isotherms were examined to describe the relationship between the adsorbent and the colored solution. Langmuir and Freundlich isotherm models are described using 
equations (3) and (4):

$\frac{C_{e}}{q_{e}}=\frac{1}{q_{m}^{b}}+\frac{1}{q_{m}} C_{e}$

$\log q_{e}=\log k_{f}+\frac{1}{n} \ln C_{e}$

Where $q_{m}$ and $b$ are Langmuir constants that are related to the maximum adsorption capacity $(\mathrm{mg} / \mathrm{g}$ ) and energy (L/mg). $K_{f}$ and $n$, are Freundlich constants which show adsorbent capacity and intensity. Microsoft Excel software was used for data analysis and drawing charts.

\section{Results}

Determining the effect of $\mathrm{pH}$ and contact time on dye removal

The effect of $\mathrm{pH}$ on the removal of RB19 in the presence of adsorbent dose $(0.4,0.8,1.2$, and $1.6 \mathrm{~g} / \mathrm{L})$ in desired dye concentrations $(25,50$, and $100 \mathrm{mg} / \mathrm{L})$ was studied and the results are shown in Figure 2. As shown in this figure, the maximum dye removal efficiency was observed at $\mathrm{pH} 3$. In the present study, the effect of the retention time $(15,30$, and 60 minutes) as one of the independent variables in dye removal was also evaluated. The maximum adsorption for both PAMAM and PPI dendrimers took place 30 and 15 minutes respectively.

The effect of adsorbent dosage

Evaluating the effect of adsorbent dosage and determining the optimal dosage of adsorbent are the most important
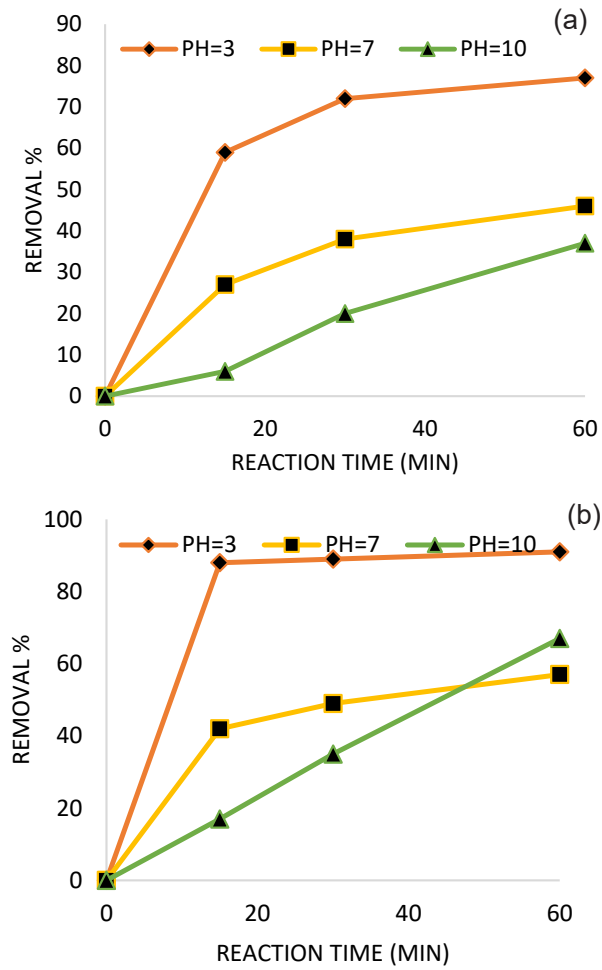

Figure 2. Effect of pH on dye removal efficiency by PAMAM (a) and $\mathrm{PPI}$ (b) dendrimers at different times. (dye concentration: $25 \mathrm{mg} / \mathrm{L}$, dendrimer dosage: $1.6 \mathrm{~g} / \mathrm{L}$ ). parameters that should be considered in the process of adsorption. The results of evaluation of the effect of adsorbent dosage on the removal of RB19 are shown in Figure 3. According to the findings of the study, by increasing adsorbent concentration from 0.4 to $1.6 \mathrm{~g} / \mathrm{L}$, dye removal efficiency by PAMAM and PPI dendrimers increased from $26 \%$ to $72 \%$ and from $35 \%$ to $88 \%$, respectively. Thus, the optimal dosage of PAMAM and PPI dendrimers was $1.6 \mathrm{~g} / \mathrm{L}$ because in the higher dosages, dye removal efficiency was constant or there was not a significant increase in dye removal.

The effect of dye concentration on the removal efficiency To survey dye adsorption efficiency, the effect of dye concentration $(25,50$, and $100 \mathrm{mg} / \mathrm{L})$ on the removal efficiency was examined. Considering that adsorption at $\mathrm{pH} 3$ had the highest efficiency, thus in this stage, adsorbent dosage $1.6 \mathrm{~g} / \mathrm{L}$ and $\mathrm{pH} 3$ were selected for dye adsorption. The results of this study are shown in Figure 4. As presented in this figure, by increasing concentrations from 25 to $100 \mathrm{mg} / \mathrm{L}$, a significant reduction in the rate of dye removal was observed. So that by increasing dye concentration, dye removal efficiency decreased from $88 \%$ to $29 \%$ by PPI and also from $72 \%$ to $23.75 \%$ by PAMAM.

Evaluation of reactive blue 19 dye adsorption isotherm Evaluation of experimental data with the Langmuir and Freundlich models and comparison of their correlation coefficients showed that RB19 dye adsorption obeyed the
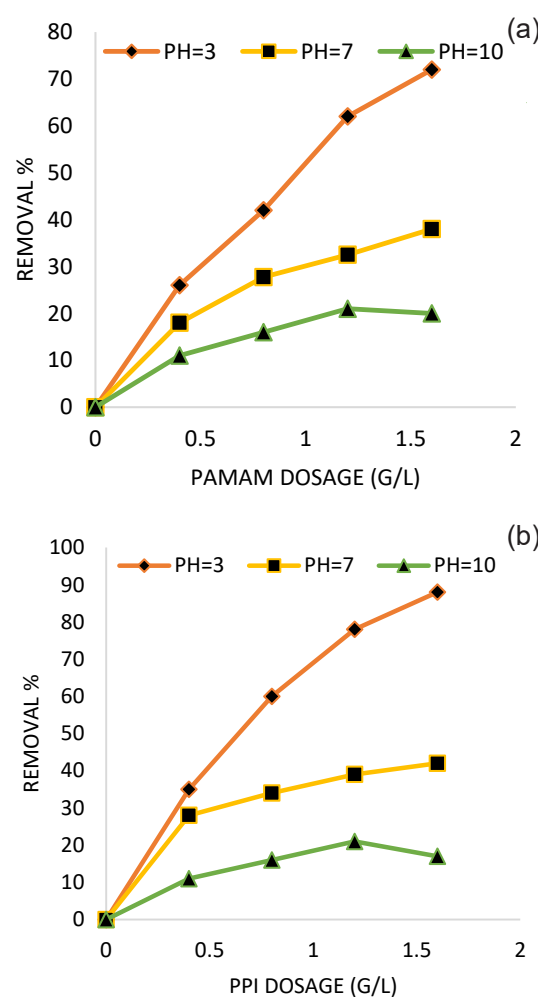

Figure 3. Effect of PAMAM (a) and PPI (b) dendrimers dosage on dye removal at different $\mathrm{pHs}$ (retention time: $30 \mathrm{~min}$, dye concentration: $25 \mathrm{mg} / \mathrm{L})$. 

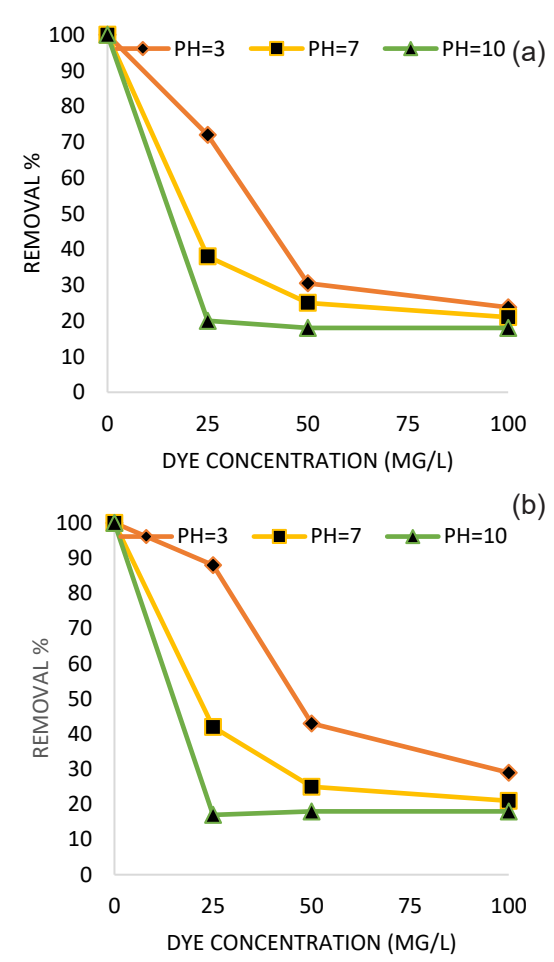

Figure 4. The effect of dye concentration on dye removal efficiency by PAMAM (a) and PPI (b) (retention time: $30 \mathrm{~min}$, dendrimer dosage: $1.6 \mathrm{~g} / \mathrm{L})$.

Langmuir isotherm by the G3 PAMAM $\left(\mathrm{R}^{2}=0.94\right)$ and PPI $\left(\mathrm{R}^{2}=0.98\right)$ dendrimers (Figure 5). Maximum adsorption was $46.8 \mathrm{mg} / \mathrm{g}$ for PAMAM and $1029 \mathrm{mg} / \mathrm{g}$ for PPI. Values of parameters of Langmuir and Freundlich isotherms are presented in Table 2 .
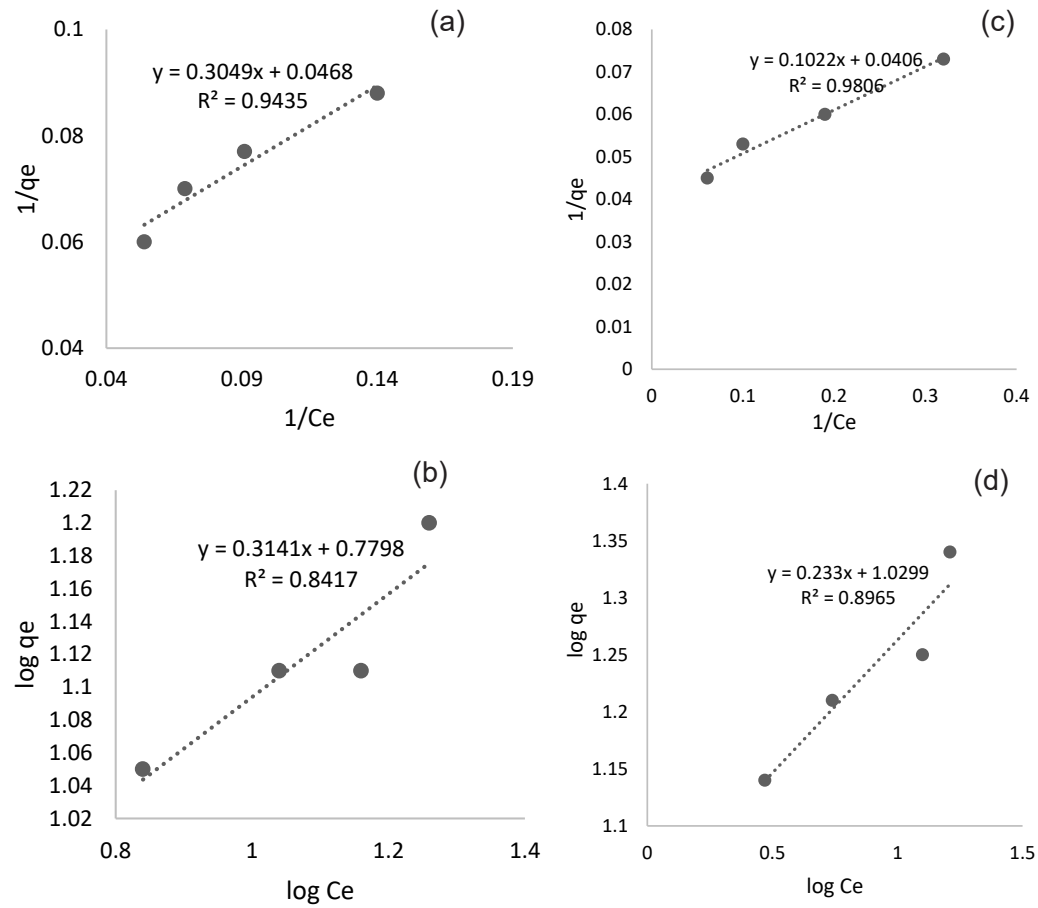

Figure 5. Adsorption isotherms of dye by PAMAM: Langmuir (a) and Freundlich (b) and by PPI: Langmuir (c) and Freundlich (d).

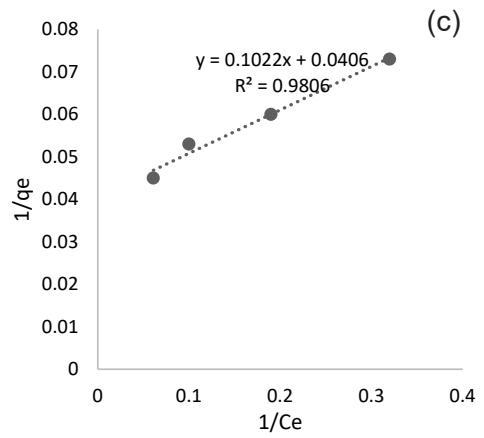

Table 2. Parameters of Langmuir and Freundlich models for RB19 dye adsorption by PPI and PAMAM dendrimers

\begin{tabular}{lccccc}
\hline & \multicolumn{2}{c}{ Langmuir isotherm } & \multicolumn{3}{c}{ Freundlich isotherm } \\
\hline & PAMAM & PPI & & PAMAM & PPI \\
\hline $\mathrm{Q}_{0}(\mathrm{mg} / \mathrm{g})$ & 46.8 & 1029 & $\mathrm{~K}_{\mathrm{F}}$ & 779.8 & 896.5 \\
$\mathrm{~K}_{\mathrm{L}}$ & 0.3049 & 0.233 & $\mathbf{n}$ & 3.18 & 4.29 \\
$\mathrm{R}^{2}$ & 0.9435 & 0.8965 & $\mathbf{R}^{2}$ & 0.84 & 0.89 \\
\hline
\end{tabular}

\section{Adsorption kinetics}

To investigate the mechanism of adsorption of the RB19 on PPI and PAMAM, the pseudo-first- and second-order models were used. Table 3 shows the Kinetic parameters of the pseudo-first- and second-order models. The results showed that the $\mathrm{R}^{2}$ values of the pseudo-second-order model ( $>0.99)$ was higher than the pseudo-first-order $(>0.90)$ for RB19 on PPI and PAMAM.

\section{Discussion}

Determining the effect of $\mathrm{pH}$ and contact time on dye removal

One of the most important effective factors in the adsorption process is $\mathrm{pH}$ that can affect adsorption capacity through affecting the degree of ionization and surface characteristics of adsorbent (18). The maximum dye removal efficiency was observed at acidic $\mathrm{pH}$. In general, it can be stated that dye removal efficiency increases when the electrostatic attraction between the dendrimer with positively charged amino groups $\left(\mathrm{NH}_{2}\right)$ and anionic dye containing negatively charged sulfonic group, $\mathrm{R}_{-} \mathrm{SO}_{3}{ }^{-}$happens. These groups produce hydrogen at acidic $\mathrm{pH}$. Generally, an increase in the $\mathrm{pH}$ leads to a

(d) 
Table 3. The first-order and second-order adsorption rate constants, calculated adsorption capacity $\left(\mathrm{q}_{\mathrm{e}}\right.$, cal $)$ and experimental adsorption capacity $\left(q_{e}\right)$ values of RB19 dye on the adsorbents

\begin{tabular}{|c|c|c|c|c|c|c|c|}
\hline \multirow{2}{*}{ Adsorbent } & \multirow{2}{*}{$q_{e, \exp }(m g / g)$} & \multicolumn{3}{|c|}{ First-order kinetic model } & \multicolumn{3}{|c|}{ Second-order kinetic model } \\
\hline & & $k_{1}(1 / \mathrm{min})$ & $\mathrm{q}_{\mathrm{e}, \mathrm{cal}}(\mathrm{mg} / \mathrm{g})$ & $\mathbf{R}^{2}$ & $k_{2}(g / m g / m i n)$ & $q_{e, \text { cal }}(m g / g)$ & $\mathbf{R}^{2}$ \\
\hline PPI & 15.31 & 0.0549 & 9.459 & 0.9062 & 0.045 & 15.037 & 0.9972 \\
\hline PAMAM & 13.28 & 0.0457 & 9.351 & 0.9111 & 0.031 & 12.82 & 0.9918 \\
\hline
\end{tabular}

decrease in the sites in the positively charged dendrimer and thus, a decrease in the dye removal efficiency $(19,20)$. In general for anionic dyes, adsorption capacity increases by reducing the $\mathrm{pH}$ of the solution while it is reverse for cationic dyes (20). Almasian et al invetigated anionic dye removal by polyacrylonitrile and PAMAM. In this study, adsorption was higher at low $\mathrm{pH}$ and $\mathrm{pH} 2.1$ was selected as the optimal pH (21). In the study of Salimpour Abkenar et al on anionic and cationic dye removal by PPI and flax, anionic dyes had better performance at $\mathrm{pH} 3$ and cationic dyes, at alkaline $\mathrm{pH}$ (pH 11) (20). Yiyun and Jiepin used different generations of PAMAM dendrimers for removal of methane dyes, and the results showed that the removal of methylene blue and fuchsia acid was effective at high $\mathrm{pH}(22)$.

The maximum adsorption for both PAMAM and PPI dendrimers took place in the first 30 and 15 minutes, respectively. In fact, at the beginning of the adsorption reactions, vacant sites in the adsorbent effectively remove the dye, but after equilibrium, due to repulsive forces between molecules of adsorbent, removal efficiency reduces $(23,24)$. In a study by Sadeghi-Kiakhani et al, G2 PPI dendrimer and chitosan were used in order to remove the reactive dye, in which by increasing the reaction time, the dye removal increased and the maximum dye removal efficiency was observed in the 30 minutes of the reaction (5). In a study by Amouei et al, removal of reactive orange 16 was evaluated by sunflower stalks. The results showed that by increasing the reaction time, color removal efficiency increased. In general, by increasing the contact time, the amount of adsorption to reach equilibrium time increased and then, remained almost constant (23).

\section{The effect of adsorbent dosage}

Evaluating the effect of adsorbent dosage and determining the optimal dosage of adsorbent are the most important parameters that should be considered in the process of adsorption. According to the findings of our study, by increasing adsorbent concentration until optimal dosage $(1.6 \mathrm{~g} / \mathrm{L})$, dye removal efficiency by PAMAM and PPI dendrimers increased. It could be due to the increased surface area of the adsorbent and the number of available active sites for adsorption (14). In the study of Ghaneian et al on the effect of adsorption of the Russian knapweed flower powderon the removal of RB19, the results showed that by increasing the adsorbent dose from 0.2 to $0.6 \mathrm{~g} / 100$ $\mathrm{mL}$, removal efficiency increased from $72 \%$ to $82 \%$ (16). In a study by Hayati et al, G2 PPI dendrimer was used for the removal of dyes from textile wastewater, and the results indicated that increasing concentrations of dendrimers leads to increased dye removal and the optimal dendrimer concentration was $1.8 \mathrm{~g} / \mathrm{L}$ (19). In another study on the adsorption of reactive red 198 by titanium dioxide nanoparticles, by increasing the adsorbent concentration, the adsorption efficiency of dye increased and the optimal adsorbent dosage was reported $1 \mathrm{~g} / \mathrm{L}$ (25), which are consistent with the results reported by Yiyun and Jiepin (22).

The effect of dye concentration on the removal efficiency The PPI dendrimers can absorb dye molecules both the protonated functional groups $\left(-\mathrm{NH}_{3}{ }^{+},>\mathrm{NH}^{+}-\right)$and the cavities. In fact, due to saturation of adsorbent active sites by the dye molecules, an increase in the dye concentration can reduce adsorption capacity or dendrimer active surfaces (20). The results of Yiyun and Jiepin showed that in low dye concentrations, removal efficiency can be increased (22). In another study by Sadeghi-Kiakhani et al on removal of reactive black 5 and reactive red 198 dyes by polypropylene (PPI) dendrimers and chitosan as biopolymer, under the optimal amounts of process parameters, dye removal was reported $97 \%$ and $99 \%$ for reactive black 5 and reactive red 198, respectively (5). The effect of crap plant powder on the removal of RB19 dye showed that by increasing the initial concentration of dye, dye removal efficiency decreased in the research of Ghaneian et al (16).

Evaluation of reactive blue 19 dye adsorption isotherm Adsorption isotherm studies have been carried out on 2 well-known Langmuir and Freundlich isotherm models. Langmuir isotherm model assumes monolayer adsorption onto a surface containing a finite number of adsorption sites of uniform strategies of adsorption with (with no interactions between the adsorbent molecules) no transmigration of adsorbate in the plane surface while Freundlich isotherm model assumes heterogeneous surface and multilayer adsorption (26). Evaluation of experimental data using the Langmuir and Freundlich models and comparison of their correlation coefficients showed that adsorption of RB19 dye obeys the Langmuir isotherm by the G3 PAMAM $\left(\mathrm{R}^{2}=0.94\right)$ and PPI $\left(\mathrm{R}^{2}=0.98\right)$ dendrimers (Figure 5).

Sayan et al examined thermodynamic adsorption in the removal of RB19 dye by activated carbon under ultrasonic irradiation. The results indicated that adsorption isotherm 
obeyed the Langmuir model and adsorption of RB19 was endothermic (26). In another study, nanocomposites including copper sulfide and PAMAM dendrimer were used to remove Isma acid fast yellow $G$ dye, and the results indicated that adsorption obeyed Langmuir model and with $\mathrm{pH}$ increase, the rate of adsorption decreased (27).

\section{Adsorption kinetics}

The results showed that the $\mathrm{R}^{2}$ values of the second-order kinetics $(>0.99)$ was higher than the first-order kinetics $(>0.90)$ for RB19 onto PPI and PAMAM. Moreover, the $q_{e}$ value is calculated adsorption capacity for pseudo-secondorder model was in agreement with the experimental $q_{e}$ values than the pseudo-first-order model. Therefore, this study suggested that the second-order model well demonstrated the adsorption of RB19 kinetics. Similar result has been observed in the adsorption of reactive dye onto carbon nanotubes (28), nickel oxide (NiO) nanoparticles (29), palm shell powder, chitosan (30) and biomass (31).

\section{Conclusion}

Removal of RB19 dye from aqueous solutions by the third generation PAMAM and PPI dendrimers was investigated. Results of this study showed that by increasing $\mathrm{pH}$, dye removal efficiency decreases and the highest dye removal efficiency was observed at $\mathrm{pH}$ 3. Also, by increasing the amount of adsorbent, dye removal efficiency increased. By increasing the initial dye concentration, dye removal efficiency decreased and by increasing the contact time, dye removal efficiency increased. In this study, the mechanism of adsorption of RB19 dye onto the third generation PAMAM and PPI dendrimers was fitted with Langmuir isotherm. According to the results, both adsorbents had good efficiency for dye removal, but PPI was more effective in removing RB19 dye. Adsorption data followed the Langmuir isotherm model. It seems that both dendrimers can be used for removal of different dyes in the textile industry as the environmental-friendly adsorbents.

\section{Acknowledgments}

The authors wish to thank Vice Chancellor of Research of Isfahan University of Medical Sciences (IUMS), Iran, for the financial support. Project code: 195093 and ethic code: IR.MUI.REC.1395.1.093.

\section{Ethical issues}

It is confirmed that this manuscript is the original work of the authors. It has not been published, nor is it under review in another journal, and it is not being submitted for publication elsewhere.

\section{Competing interests}

The authors declare that they have no conflicts of interests.

\section{Authors' contributions}

All authors contributed equally to the study design, data collection, analysis, and interpretation. All authors critically reviewed, refined, and approved the manuscript.

\section{References}

1. Hadjltaief HB, Galvez ME, Zina MB, Da Costa P. TiO2/clay as a heterogeneous catalyst in photocatalytic/photochemical oxidation of anionic reactive blue 19. blue 19. Arab J Chem 2014;1-9. doi: 10.1016/j.arabjc.2014.11.006.

2. Malakootian M, Jafari Mansoorian H, Hosseini A, Khanjani $\mathrm{N}$. Evaluating the efficacy of alumina/carbon nanotube hybrid adsorbents in removing Azo reactive red 198 and blue 19 dyes from aqueous solutions. Process Saf Environ Prot 2015; 96: 125-37. doi: 10.1016/j.psep.2015.05.002.

3. Maleki A, Mahvi AH, Rezaee R, Davari B. Removal of reactive blue 19 using natural and modified zeolites. Iranian Journal of Health and Environment 2013; 5(4): 519-30. [In Persian].

4. Khalque A, Ahammed SS, Khan SA, Awual R, Islam E, Rahman L. Utilizing Aman Husk for efficient removal of reactive dyes from industrial wastewater. Global Journal for Research Analysis 2018; 7(2): 663-5.

5. Sadeghi-Kiakhani M, Arami M, Gharanjig K. Dye removal from colored-textile wastewater using chitosan-PPI dendrimer hybrid as a biopolymer: optimization, kinetic, and isotherm studies. J Appl Polym Sci 2013; 127(4): 260719. doi: 10.1002/app.37615.

6. Srikantan C, Suraishkumar GK, Srivastava S. Effect of light on the kinetics and equilibrium of the textile dye (reactive red 120) adsorption by Helianthus annuus hairy roots. Bioresour Technol 2018; 257: 84-91. doi: 10.1016/j. biortech.2018.02.075.

7. Vunain E, Mishra AK, Mamba BB. Dendrimers, mesoporous silicas and chitosan-based nanosorbents for the removal of heavy-metal ions: a review. Int J Biol Macromol 2016; 86:570-86. doi: 10.1016/j.ijbiomac.2016.02.005

8. Malakootian M, Hashemi M, Toolabi A, Nasiri A. Investigation of nickel removal using poly(amidoamine) generation 4 dendrimer (PAMAM G4) from aqueous solutions. Journal of Engineering Research 2018; 6(2): 1323.

9. Taghavi Pourian Azar N, Mutlu P, Khodadust R, Gunduz U. Poly(amidoamine) (PAMAM) Nanoparticles: Synthesis and Biomedical Applications. Hacettepe Journal of Biology and Chemistry 2013; 41(3): 289-99.

10. Sounthararajah DP, Loganathan P, Kandasamy J, Vigneswaran S. Adsorptive removal of heavy metals from water using sodium titanate nanofibres loaded onto GAC in fixed-bed columns. J Hazard Mater 2015; 287: 306-16. doi: 10.1016/j.jhazmat.2015.01.067.

11. Hayati B, Arami M, Maleki A, Pajootan E. Application of dendrimer/titania nanohybrid for the removal of phenol from contaminated wastewater. Desalination and Water Treatment 2016; 57(15): 6809-19. doi: 10.1080/19443994.2015.1012746.

12. Sajid M, Nazal MK, Ihsanullah I, Baig N, Osman AM. Removal of heavy metals and organic pollutants from water using dendritic polymers based adsorbents: a critical review. Sep Purif Technol 2018; 191:400-23. doi.org/10.1016/j. 
seppur.2017.09.011.

13. Patel R, Patel H, Gajjar D, Patel PM. Removal of $\mathrm{CU}^{2+}, \mathrm{Ni}^{2+}$ and $\mathrm{Zn}^{2+}$ metal ions from water by hydroxyl terminated s-triazine based dendrimer. Malaysian Polymer Journal 2014; 9(2): 70-7.

14. Wang $\mathrm{P}, \mathrm{Ma} \mathrm{Q}, \mathrm{Hu} \mathrm{D}$, Wang L. Removal of reactive blue 21 onto magnetic chitosan microparticles functionalized with polyamidoamine dendrimers. React Funct Polym 2015; 9192: 43-50. doi: 10.1016/j.reactfunctpolym.2015.04.007.

15. Lee S, Han SY, Lee TG, Chung G, Lee D, Oh HB. Observation of pronounced $b^{\star}, y$ cleavages in the electron capture dissociation mass spectrometry of polyamidoamine (PAMAM) dendrimer ions with amide functionalities. J Am Soc Mass Spectrom 2006; 17(4): 536-43. doi: 10.1016/j. jasms.2005.12.004.

16. Ghaneian MT, Dehvari M, Jourabi Yazdi N, Mootab M, Jamshidi B. Evaluation of efficiency of Russian knapweed flower powder in removal of reactive blue 19 from synthetic textile wastewater. Journal of Rafsanjan University of Medical Sciences 2014; 12(10): 831-42. [In Persian].

17. Nadafi K, Nabizadeh Nodehi R, Jahangiri-Rad M. Removal of Reactive Blue 29 Dye from Water by Single-Wall Carbon Nanotubes. Iranian Journal Health and Enviroment 2011; 4(3): 359-68. [In Persian].

18. Ghaneian MT, Jasemizadeh T, Sahlabadi F, Miri M, Motabbefroee M. Survey thef efficiency of barberry stem powder in removal of the reactive Blue 19 from textile industrial wastewater. Journal of Rafsanjan University of Medical Sciences 2014; 13(7): 631-40. [In Persian].

19. Hayati B, Mahmoodi NM, Arami M, Mazaheri F. Dye removal from colored textile wastewater by poly(propylene imine) dendrimer: operational parameters and isotherm studies. CLEAN - Soil Air Water 2011; 39(7): 673-9. doi: 10.1002/clen.201000182.

20. Salimpour Abkenar S, Malek RM, Mazaheri F. Dye adsorption of cotton fabric grafted with PPI dendrimers: isotherm and kinetic studies. J Environ Manage 2015; 163: 53-61. doi: 10.1016/j.jenvman.2015.08.003.

21. Almasian A, Olya ME, Mahmoodi NM. Synthesis of polyacrylonitrile/polyamidoamine composite nanofibers using electrospinning technique and their dye removal capacity. J Taiwan Inst Chem Eng 2015; 49: 119-28. doi: 10.1016/j.jtice.2014.11.027.

22. Yiyun C, Jiepin Y. Effect of polyamidoamine dendrimers in decolorising triarylmethane dye effluent. Coloration Technology 2005; 121(2): 72-5. doi: 10.1111/j.14784408.2005.tb00254.x.

23. Amouei A, Asgharnia HA, Karimian K, Mahdavi Y, Balark D, Ghasemi SM. Optimization of dye reactive orange 16 (RO16) adsorption by modified sunflower stem using response surface method from aqueous solutions. Journal of Rafsanjan University of Medical Sciences 2016; 14(10): 813-26. [In Persian]

24. Mahmoodi NM, Hayati B, Arami M, Mazaheri F. Single and Binary system dye removal from colored textile wastewater by a dendrimer as a polymeric nanoarchitecture: equilibrium and kinetics. J Chem Eng Data 2010; 55(11): 4660-8. doi: 10.1021/je100248m.

25. Ghaneian MT, Ehrampush MH, Rahimi S, Ghanizadeh GH, AsKarshahi M. Absorbtion of reactive red 198 by nano titanium dioxide from of wastewater. Journal of Tolo Behdasht 2011; 9(4): 59-70. [In Persian].

26. Sayan E, Nuri Ata O, Esra Edecan M. Investigation of adsorption thermodynamics on removal of reactive blue 19 onto activated carbon under ultrasonic irradiation. J Chem Soc Pak 2014; 36(2): 232-8.

27. Abou Taleb MF, El-Trass A, El-Sigeny S. Synthesis of polyamidoamine dendrimer (PAMAM/CuS/AA) nanocomposite and its application in the removal of Isma acid fast yellow G Dye. Polym Adv Technol 2015; 26(8): 994-1002. doi: 10.1002/pat.3517.

28. Wu CH. Adsorption of reactive dye onto carbon nanotubes: equilibrium, kinetics and thermodynamics. J Hazard Mater 2007; 144(1-2): 93-100. doi: 10.1016/j.jhazmat.2006.09.083.

29. Monsef Khoshhesab Z, Ahmadi M. Removal of reactive blue 19 from aqueous solutions using $\mathrm{NiO}$ nanoparticles: equilibrium and kinetic studies. Desalination and Water Treatment 2016; 57(42): 20037-48. doi: 10.1080/19443994.2015.1101713.

30. Sreelatha G, Ageetha V, Parmar J, Padmaja P. Equilibrium and Kinetic studies on reactive dye adsorption using palm shell powder (an agrowaste) and chitosan. J Chem Eng Data 2010; 56(1): 35-42. doi: 10.1021/je1007263.

31. Mustafa MM, Jamal P, Alkhatib MF, Mahmod SS, Jimat DN, Ilyas NN. Panus tigrinus as a potential biomass source for reactive blue decolorization: isotherm and kinetic study. Electron J Biotechnol 2017; 26: 7-11. doi: 10.1016/j. ejbt.2016.12.001. 